\title{
Therapeutic Decision Making in a New Drug Era in Multiple Sclerosis
}

\author{
B. Mark Keegan, MD, $\operatorname{FRCP}(C)^{1}$ \\ ${ }^{1}$ Department of Neurology, Mayo Clinic, Rochester, Minnesota \\ Semin Neurol 2013;33:5-12.
}

\begin{abstract}
Address for correspondence B. Mark Keegan, MD, FRCP(C), Department of Neurology, Mayo Clinic, 200 First Street SW, Rochester, MN, 55905 (e-mail: keegan.bmark@mayo.edu).
\end{abstract}

\begin{abstract}
Keywords

- multiple sclerosis (MS)

- diagnosis

- therapy

Multiple sclerosis is a presumed autoimmune, inflammatory disease of the central nervous system. Since the early 1990s, medications have been devised, tested, and approved for relapsing forms of multiple sclerosis (MS). MS treatments work by altering the immune system to reduce inflammatory MS activity, thus curtailing clinical relapses (attacks), thereby reducing short-term disability related to the MS attacks. The promise of long-term improvement in MS-related disability remains the most desirable therapeutic goal; to what degree current MS therapies are effective in reducing this is controversial. Recent years have seen a surge in novel MS therapies delivered both parenterally and orally that offer new therapeutic alternatives to MS patients and their treating providers. It remains essential to make an unequivocal diagnosis of MS and identify its clinical course prior to initiating therapies. Switching and altering MS therapies can now be done by rational approaches based on therapeutic efficacy and tolerability; however, these remain nonevidence-based for the most part. The high cost of MS therapies remains a significant concern. A new therapeutic era is at hand offering new hope for patients affected by this chronic, frequently disabling disease.
\end{abstract}

New drugs available for relapsing forms of multiple sclerosis have broadened the therapeutic armamentarium for this chronic inflammatory condition. This brings more therapeutic challenges for the clinical decision makers and their respective patients.

\section{Making the Correct Diagnosis}

The first and most critical decision in making the appropriate recommendations for patients with possible multiple sclerosis is clarifying the exact diagnosis. - Fig. 1 demonstrates a three-step approach in addition to published formal guidelines regarding diagnosis of multiple sclerosis, such as the revised McDonald diagnostic criteria. ${ }^{1}$

The first step in a simplified diagnostic process is identifying what may be termed the classical cardinal clinical features that are highly suggestive and particularly informative of a possible diagnosis of multiple sclerosis. For example, one common heralding clinical MS symptom is inflammatory optic neuritis. This typically presents with painful monocular visual loss that usually worsens over hours to days. The maintenance of visual impairment may last for days to weeks, and then improve, often with complete clinical recovery either spontaneously or with the use of high-dose intravenous or oral corticosteroids. ${ }^{2,3}$ Other classical cardinal features include painless binocular diplopia, hemiparesis, hemisensory deficit, or symptoms of acute myelopathy with a spinal sensory level, paraparesis and quadriparesis, and bladder and/or bowel disturbance, all lasting at least 24 hours but generally days to weeks in duration. Insidiously progressive symptoms of gait impairment due to a progressive myelopathy over many months and years are common features of primary or secondary progressive forms of multiple sclerosis (primary progressive MS [PPMS], secondary progressive MS [SPMS]). Mild memory impairment and fatigue are both extremely common in MS, but are typically not considered highly defining clinical features as they occur in many conditions and are regarded as being highly prevalent, but rather nonspecific. Occasionally, patients may have primary
Issue Theme Current and Emerging Therapies for Multiple Sclerosis; Guest Editor, B. Mark Keegan, MD, FRCP(C)
Copyright (c) 2013 by Thieme Medical Publishers, Inc., 333 Seventh Avenue, New York, NY 10001, USA. Tel: +1(212) 584-4662.
DOI http://dx.doi.org/ 10.1055/s-0033-1345709. ISSN $0271-8235$. 


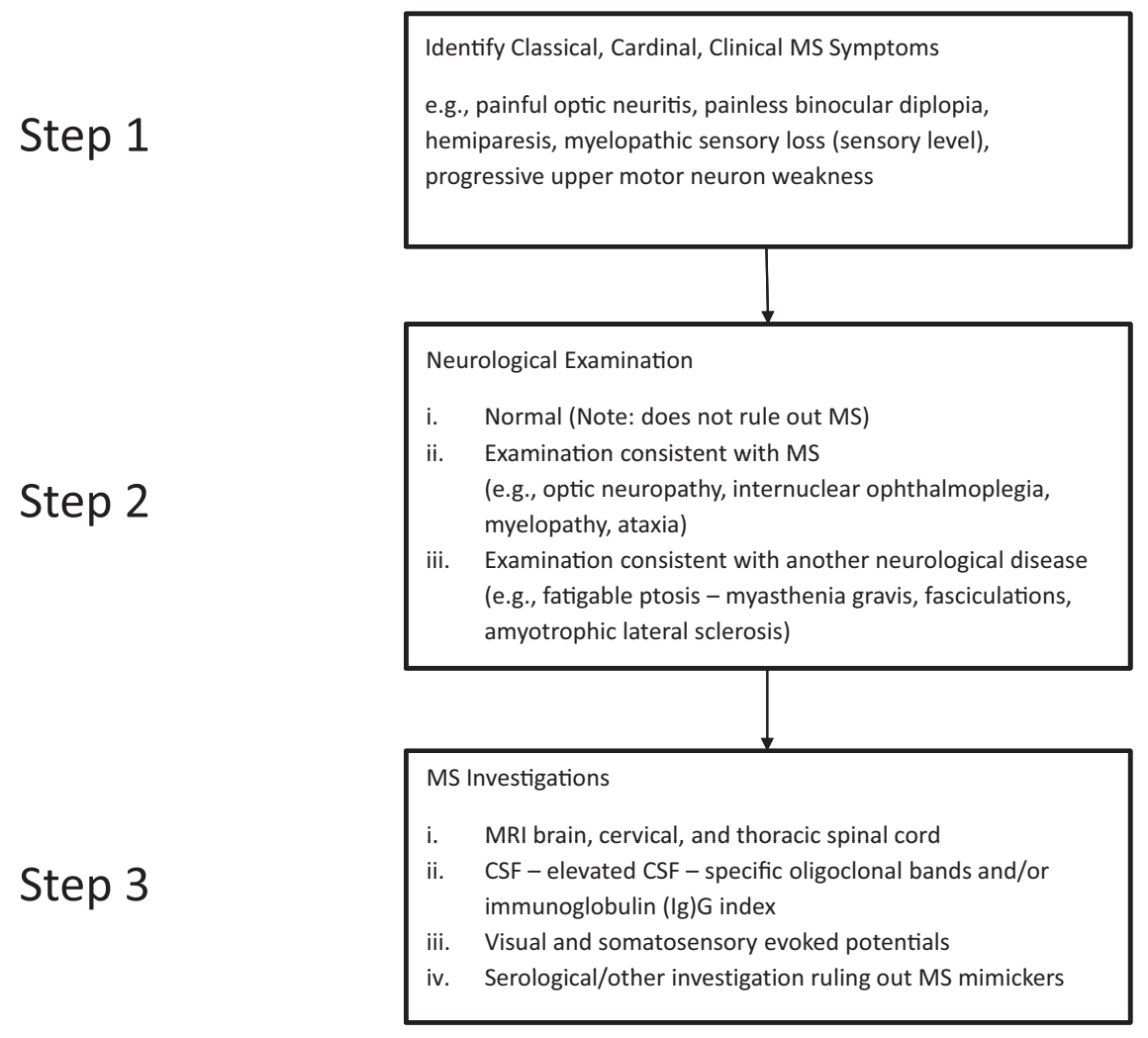

Fig. 1 A simplified three-step method to diagnose multiple sclerosis (MS). CSF, cerebrospinal fluid.

progressive cognitive dysfunction that is severe, ${ }^{4}$ but this is far less common than the symptoms listed above.

Following a comprehensive clinical history and identification of the classical cardinal clinical features of multiple sclerosis, a detailed neurologic examination is required. Although the results of neurologic examination may be complicated to describe, the resultant examination may be simplified by considering three separate results: a normal neurologic examination, an examination highly suggestive of MS as the underlying diagnosis, and an examination that highly suggests an alternative neurologic diagnosis. The first presentation would be that of an entirely normal neurologic examination. It should be noted that the first examination scenario certainly does not rule out multiple sclerosis as an underlying diagnosis as many patients with unequivocal multiple sclerosis will have an entirely normal neurologic examination. The clinical neurologic examination features that would highly suggest, but are in no way definitively diagnostic of multiple sclerosis include signs of optic neuropathy (e.g., central scotoma, acuity loss, color vision impairment and relative afferent pupillary defect), internuclear ophthalmoplegia-particularly bilateral internuclear ophthalmoplegia, cerebellar gait ataxia, upper motor neuron hemiparesis, paraparesis or quadriparesis, and spinal sensory level and other signs of myelopathy with bilateral extensor plantar responses. Finally, neurologic physical examination features that would be more likely diagnostic of other competing neurologic conditions such as fatigable ptosis in myasthenia gravis, or prominent fasciculations of amyotrophic lateral sclerosis need to be ruled out.
The final step includes specific investigations that yield results highly suggestive of multiple sclerosis. The most critical and specific investigations are brain, cervical, and thoracic spine magnetic resonance imaging (MRI). Some patients' evaluations may require only selected components of brain and spinal cord MRI. However, it should be noted that a lumbar spine MRI scan would not be needed in terms of ruling out or in multiple sclerosis, and that thoracic spine neuroimaging can be an important investigation that is often left unpursued. Typical MRI findings include periventricular, juxtacortical, and infratentorial brain lesions and ovoid short segment (less than three vertebral columns) hemicord lesions within the cervical and thoracic spinal cord. ${ }^{5}$ Development of new MRI T2 lesions, gadolinium-enhancing T1 lesions, and T1 hypointensities ("black holes"), as well as brain and spinal cord atrophy are further neuroimaging evidence of MS.

Cerebrospinal fluid (CSF) assessment is important in the evaluation of many MS cases to define evidence of an autoimmune, inflammatory process being generated intrathecally. ${ }^{6}$ Specifically, identification of elevations in unique CSF oligoclonal bands and immunoglobulin $\mathrm{G}$ ( IgG) index are considered characteristic, although not diagnostic of, multiple sclerosis. Importantly, CSF abnormalities such as substantial elevations in white blood cell count might indicate an infectious or an alternative chronic inflammatory cause, and marked elevations in protein may occur in compressive myelopathies with CSF block or other infectious and inflammatory diseases.

Neurophysiological evaluation with evoked potentials may still contribute to MS diagnosis. ${ }^{7}$ This includes visual 
evoked potentials to identify conduction deficit in the optic nerves on either side. Somatosensory evoked potentials are occasionally beneficial in identifying impaired central spinal cord conduction. Generally speaking, brainstem auditory evoked potentials have become decreasingly important in the evaluation of multiple sclerosis.

Finally, serological evaluations and further radiologic or other investigations searching for systemic diseases known to be MS mimickers may be required. ${ }^{8}$ One general guideline is the number of serological evaluations and other investigations that may be required to make a diagnosis of multiple sclerosis is inversely proportional to the pretest certainty that the diagnosis is multiple sclerosis. This means that in very certain cases, limited or no serological evaluations may be needed. In very challenging cases, where a diagnosis is clearly uncertain, an expanded number of evaluations may be needed to identify infectious, vascular, traumatic, neoplastic, inherited, and other causes that may mimic multiple sclerosis. Detailed evaluations for MS mimickers are beyond the scope of this article.

\section{Identifying the Clinical Course of Multiple Sclerosis}

After ruling out potential MS mimickers that may complicate a confident diagnosis of MS, the clinician must then identify the MS clinical course. The patient's current MS clinical course is critical to assess whether currently available immunotherapies will reliably benefit the patient (i.e., those with clinical and or radiologic evidence of relapsing inflammatory MS). Clinical course presentations of MS-related disease range from solely MRI findings without any prior history of clinical attacks or neurologic abnormalities (radiologically isolated syndrome [RIS]) to single attack (clinically isolated syndrome [CIS]) to multiple clinical attacks with maintained stability between attacks (relapsing remitting MS [RRMS]) and those without clinical attacks, but predominantly or only progressive neurologic worsening more consistent with neurodegenerative diseases (PPMS and SPMS).

\section{Radiologically Isolated Syndrome}

One clinical scenario arising in the evaluation of MS is that of a patient without characteristic clinical cardinal symptoms or signs of MS attacks or of progressive MS. Also described as "asymptomatic" MS or "radiologic onset" MS, these patients have MRI done for alternative reasons than MS (e.g., migraine, controls for MRI research investigations), but are found to have lesions highly typical of MS on neuroimaging. MRI findings may even fully satisfy the Barkhof-Tintore radiologic diagnostic criteria of MS and may include asymptomatic spinal cord lesions and abnormalities on CSF examination consistent with MS (elevated unique CSF oligoclonal bands and/or IgG index). Patients with RIS are at risk to have a future clinical attack diagnostic of MS of $\sim 30 \%$ over 5 years ${ }^{9,10}$ and higher in those with asymptomatic spinal cord lesions. ${ }^{11}$ Given the uncertainty in confirming later diagnosis, and importantly, prognosis in these cases, currently most clinicians do not recommend immunomodulatory medications be initiated unless multiple new lesions are developing rapidly over time or alternatively, a definite clinical attack occurs diagnostic of relapsing remitting MS (RRMS).

\section{Clinically Isolated Syndrome}

Clinically isolated syndrome is the term given the clinical course where patients have experienced only one characteristic clinical attack of demyelination (e.g., new-onset optic neuritis, cerebral demyelination, brainstem syndrome, or acute myelopathy). ${ }^{12}$ This entity has been extensively studied, and it is clear that the risk to develop MS depends upon MRI findings at CIS onset. ${ }^{13}$ The risk for patients with $\geq 2$ lesions are at high risk to develop RRMS based on either a new relapse characteristic of MS or new MS MRI lesions. Those with one or no accompanying MRI lesions are at lower risk for future RRMS; in fact, those with the low-risk profile that later develop RRMS appear to have a relatively less severe later clinical course. The diagnosis of CIS has been curtailed by the most recent revision to the diagnostic criteria for MS that allow a diagnosis of RRMS at the time of a single clinical attack when there is MRI evidence of both new (gadolinium-enhancing T1 lesions) and old (nongadolinium-enhancing T2 lesions) lesions simultaneously appearing that satisfy criteria for dissemination in time. ${ }^{1}$

Treatment with either $\beta$ interferons or glatiramer acetate may be considered for CIS patients with high-risk abnormal MRI at onset as described above. These agents have been shown to reduce the short-term likelihood of further new MRI lesions and development of further clinical attacks diagnostic of RRMS. ${ }^{14-16}$

\section{Relapsing Remitting Multiple Sclerosis}

RRMS is the most common clinical scenario encountered and the most common indication for immunomodulatory MS therapies. At least $85 \%$ of MS patients present with this clinical course, which is confirmed by either two or more clinical attacks or a single clinical attack accompanied by MRI evidence of inflammatory disease activity disseminated in time and space within the central nervous system. It is important to distinguish RRMS from SPMS. RRMS displays complete clinical stability between relapse-related attacks and any clinical impairment comes exclusively from relapserelated, acute inflammatory disease. Occasionally, clinical evidence of relapses is lacking and MRI findings may aid in assessing an ongoing inflammatory activity contributing to clinical worsening. Progressive clinical worsening of impairment that is not due to acute inflammatory disease (clinical attacks and/or prominent new MRI activity) suggests SPMS.

\section{Secondary Progressive Multiple Sclerosis}

A majority of RRMS patients develop insidiously progressive impairment typically many years following disease onset. A progressive myelopathic course is the most common clinical manifestation, although progressive ataxia or cognitive impairment can alternatively be seen. This progressive clinical worsening comes in the absence of noticeable inflammatory activity (i.e., clinical relapses and/or new MRI lesion development). Overall, the most substantial degree of MS-related 
morbidity is due to progressive forms of MS. Documentation of at least one definite clinical MS attack in the past (many have had multiple attacks) distinguishes SPMS from PPMS. Currently available MS therapies do not appear to have any robust effect on purely progressive SPMS, while there may be some rationale for medications in those SPMS patients with ongoing relapses or substantial ongoing accrual of new MRI inflammatory lesions.

\section{Primary Progressive Multiple Sclerosis}

PPMS patients present with progressive myelopathic gait dysfunction, cerebellar ataxia, or cognitive impairment without clear history of any clinical attacks. ${ }^{17}$ The revised McDonald criteria requires that the clinical progression must be of at least 1 year's duration and be accompanied by a combination of brain and spinal cord MRI abnormalities and/or CSF examination consistent with MS. Obvious inflammatory activity is lower in PPMS patients as evidenced both by the lack of clinical relapses as well as the relative paucity of MRI lesions compared with RRMS and SPMS. Currently, there are no immunomodulatory medications approved by the U.S. Food and Drug Administration (FDA) for PPMS. ${ }^{18}$ Occasionally, however, particularly in young patients, a progressive clinical course may be accompanied by MRI findings of marked, acute inflammatory changes with numerous gadolinium-enhancing T1 and new T2 lesion accumulation. It is considered that perhaps these patients have an inflammatory MS that could be considered for immunomodulatory MS medication initiation.

\section{Deciding on Which Medication}

\section{Determine Therapeutic Goals}

The main therapeutic goals of immunomodulatory MS therapies are to reduce clinical relapses and accumulation of new MRI lesions. MRI findings of encouraging therapeutic response include reduction in the development of new T2 lesions, gadolinium-enhancing T1 lesions, and T1 hypointensities, as well as brain and spinal cord atrophy that may either accompany focal MS lesions or be diffuse. An additional goal is to reduce short-term relapse-related disability with a long-term promise (continuing to be controversial) of reducing long-term disability regardless of relapse or progression-related etiology. Controversy remains evidenced by somewhat conflicting study findings; some support a long-term beneficial effect for initial immunomodulatory medications such as $\beta$ interferons, while others do not. ${ }^{19,20}$

\section{How Do You Determine If Therapeutic Goals Are Being Met?}

A detailed clinical history will document a relapse rate prior to and following initiation of MS therapy. However, caution needs to be used as patient recall may be incomplete. Clinicians also need to be aware of the tendency for regression to the mean number of attacks: Simply by nature of the disease, patients with a prior high relapse rate will tend to experience fewer "baseline" attacks even without altering therapy. Additionally, RRMS patients will experience fewer attacks as they age.

Gauging improvement or stability in neurologic impairment is gained both from history and neurologic examination. Assessing functional ambulatory limitations is often a key historical element. The clinician may assess functional ambulatory limitations by history indicating progressive disease. As years go on, the leg dragging or ataxia will be noticed progressively earlier at the one mile, half mile, quarter mile mark that indicates clinical progression.

MRI findings may inform the clinician regarding especially ongoing and new inflammatory activity. This is evidenced by gadolinium-enhancing T1 lesions, accumulating new T2 lesions, and T1 hypointensities. Brain and spinal cord atrophy on MRI may also become apparent progressively over time. Although an ideal interval for serial MRI evaluations is not defined; some physicians recommend every 12 to 24 months for "average-activity" MS patients to assess radiologic stability, worsening, or improvement over time relating to the patients' therapies. Some patients with highly active MS or those on natalizumab (especially to check for early progressive multifocal leukoencephalopathy [PML] development) may require brain MRI more frequently.

Certainly, if the goals of immunomodulatory or symptomatic therapy are being met, then no changes would be required unless there are significant problems with medication tolerability. This remains a challenge for all the immunomodulatory MS medications to varying degrees ( $\mathbf{-}$ Table $\mathbf{1}$ ). A detailed evaluation of common and idiopathic side effects associated with the medication will be required and further switching of medications based on adherence and tolerability may be needed.

\section{If Goals Are Not Being Met}

There are several reasons why therapeutic goals may not be being achieved. If the pretherapy relapse rate is not improved, a therapeutic switch may be indicated. Importantly though, the relapse rate is an incomplete indicator of the ongoing inflammatory disease activity. Brain and spinal cord MRI may be revealing of an active inflammatory component that is incompletely controlled even when the relapse rate is improved or relapses are nonexistent. An alteration and switch of medications to a more powerful antiinflammatory medication in these patients may be indicated despite the lack of clinical attacks or definitive worsening disability if the MRI shows therapy-resistant inflammatory disease.

\section{Is Clinical Worsening due to Attack-Related Disease or Progression?}

If patients are clinically worsening (an indication of not meeting therapeutic goals), it must be distinguished whether this is due to relapse-related disease or relatively noninflammatory MS progressive disease. If it is due to progression only, it is generally presumed that pathophysiologically the disease is neurodegenerative in nature or is due to subclinical (and subradiologic) inflammation that is not clearly responsive to our currently available therapies. If 
Table 1 Approved MS Medications

\begin{tabular}{|c|c|c|c|c|}
\hline Indication & Drug and dosage & $\begin{array}{l}\text { Laboratory prior to } \\
\text { therapy }\end{array}$ & $\begin{array}{l}\text { Laboratory during } \\
\text { therapy }\end{array}$ & Side effects \\
\hline RRMS-CIS & $\begin{array}{l}\text { Interferon } \beta 1 \text {-a } \\
\text { (Avonex) } \\
30 \mu \mathrm{g} \text { IM weekly } \\
\text { or } \\
\text { (Rebif) } \\
22 \text { or } 44 \mu \mathrm{g} \text { SC } \\
3 \text { times weekly }\end{array}$ & CBC, liver enzymes, TSH & $\begin{array}{l}\text { CBC, liver enzymes } 1^{\text {st }} \\
\text { week, at } 1 \text { month, } \\
\text { then every } 3 \text { mo }\end{array}$ & $\begin{array}{l}\text { Injection site reaction, } \\
\text { fever, myalgia, chills, } \\
\text { asthenia, depression }\end{array}$ \\
\hline RRMS-CIS & $\begin{array}{l}\text { Interferon } \beta 1-b \\
\text { (Betaseron, Extavia) } \\
8 \text { MIU SC every other day }\end{array}$ & $\begin{array}{l}\mathrm{CBC} \text {, liver enzymes, TSH } \\
\text { at } 6 \text { months }\end{array}$ & $\begin{array}{l}\text { CBC, liver enzymes } 1^{\text {st }} \\
\text { week, at } 1 \text { month, } \\
\text { then every } 3 \text { mo }\end{array}$ & $\begin{array}{l}\text { Injection site reaction, } \\
\text { fever, myalgia, chills, } \\
\text { menstrual irregularities, } \\
\text { depression }\end{array}$ \\
\hline RRMS-CIS & $\begin{array}{l}\text { Glatiramer acetate } \\
\text { (Copaxone) } \\
20 \text { mg SC daily }\end{array}$ & None & None & $\begin{array}{l}\text { Injection site reaction, } \\
\text { lipoatrophy, flushing, } \\
\text { transient chest pain and } \\
\text { dyspnea, eosinophilia }\end{array}$ \\
\hline RRMS & $\begin{array}{l}\text { Natalizumab (Tysabri) } \\
300 \text { mg IV every } 4 \text { wk }\end{array}$ & $\begin{array}{l}\text { TOUCH }^{\circledR} \text { prescribing } \\
\text { program Serum JCV } \\
\text { antibodies }\end{array}$ & $\begin{array}{l}\text { Serum JCV antibodies } \\
\text { every } 6 \text { mo if JCV } \\
\text { seronegative }\end{array}$ & $\begin{array}{l}\text { Allergic reaction, pro- } \\
\text { gressive multifocal } \\
\text { leukoencephalopathy }\end{array}$ \\
\hline RRMS & $\begin{array}{l}\text { Fingolimod (Gilenya) } \\
0.5 \text { mg po once daily, first } \\
\text { dose at least } 6 \text { h heart rate } \\
\text { and blood-pressure } \\
\text { monitoring }\end{array}$ & $\begin{array}{l}\text { Liver enzymes, ECG, se- } \\
\text { rum VZV-IgG, ophthal- } \\
\text { mologic exam for } \\
\text { macular edema, } \\
\text { repeated at 3-4 mo }\end{array}$ & $\begin{array}{l}\text { Ophthalmologic exam } \\
\text { for macular edema, } \\
\text { repeated at } 3-4 \text { mo } \\
\text { (annually with uveitis } \\
\text { or diabetes mellitus) }\end{array}$ & $\begin{array}{l}\text { Headache, flu, diarrhea, } \\
\text { back pain, liver enzyme } \\
\text { elevations, and cough. } \\
\text { Bradycardia, viral } \\
\text { infections. }\end{array}$ \\
\hline RRMS & $\begin{array}{l}\text { Teriflunomide (Aubagio) } \\
7 \mathrm{mg} \text { or } 14 \mathrm{mg} \text { po once } \\
\text { daily }\end{array}$ & $\begin{array}{l}\text { CBC, liver enzymes, tu- } \\
\text { berculin skin test, preg- } \\
\text { nancy test (women of } \\
\text { child-bearing potential) }\end{array}$ & $\begin{array}{l}\text { Monthly liver enzymes } \\
\text { for } 6 \text { mo, }\end{array}$ & $\begin{array}{l}\text { Diarrhea, abnormal liver } \\
\text { tests, nausea, influenza, } \\
\text { alopecia, potential for } \\
\text { hepatotoxicity, may } \\
\text { cause significant birth } \\
\text { defects if used during } \\
\text { pregnancy, peripheral } \\
\text { neuropathy, transient } \\
\text { acute renal failure, and } \\
\text { hyperkalemia }\end{array}$ \\
\hline RRMS & $\begin{array}{l}\text { BG-12 (Tecfidera) } \\
120 \text { mg po twice daily for } 7 \\
\text { d, then } 240 \text { mg po twice } \\
\text { daily }\end{array}$ & $\mathrm{CBC}$ & CBC annually & $\begin{array}{l}\text { Flushing, abdominal } \\
\text { pain, nausea, diarrhea }\end{array}$ \\
\hline $\begin{array}{l}\text { RRMS/SPMS } \\
\text { (with severe } \\
\text { worsening, often } \\
\text { with relapses) }\end{array}$ & $\begin{array}{l}\text { Mitoxantrone (Novantrone) } \\
5 \text { or } 12 \mathrm{mg} / \mathrm{m}^{2} \text { IV every } 3 \mathrm{mo} \\
\text { Maximum lifetime cumula- } \\
\text { tive dose } 100 \mathrm{mg} / \mathrm{m}^{2}\end{array}$ & $\begin{array}{l}\text { CBC, liver enzymes, } \\
\text { creatinine, ECG, } \\
\text { transthoracic } \\
\text { echocardiogram }\end{array}$ & $\begin{array}{l}\text { CBC (hold if neutrophil } \\
\text { count }<1500 / \mathrm{mm}^{3} \text { ), } \\
\text { liver enzymes, creati- } \\
\text { nine weekly for } 1 \text { mo } \\
\text { following each dose, } \\
\text { ECG and cardiac ejec- } \\
\text { tion fraction every } 3 \\
\text { mo, D } / C \text { if ejection } \\
\text { fraction }<50 \%\end{array}$ & $\begin{array}{l}\text { Myelosuppression, nau- } \\
\text { sea, alopecia, secondary } \\
\text { amenorrhea, cardiotox- } \\
\text { icity, hematologic } \\
\text { malignancies }\end{array}$ \\
\hline
\end{tabular}

Abbreviations: CBC, complete blood count; CIS, clinically isolated syndrome; D/C, discontinue; ECG, electrocardiogram; IM, intramuscularly; IV, intravenously; JCV, John Cunningham virus; po, by mouth; RRMS, relapsing remitting multiple sclerosis; SC, subcutaneously; SPMS, secondary progressive multiple sclerosis; TSH, thyroid-stimulating hormone blood test.

it is solely due to progressive disease, then it appears that switching to an alternative MS therapy is unlikely to benefit. Conversely, if clinical impairment is strongly associated with ongoing relapses or marked new inflammatory MRI activity, then enhancing antiinflammatory effectiveness by an "upgrade" in intensity of immunomodulatory therapy would be needed.

\section{How Are MS Medications Selected?}

Various preparations of injectable $\beta$ interferons and glatiramer acetate remain the first-line immunomodulatory medications for many clinicians (-Fig. 2). ${ }^{21}$ These injectable therapies come along with now decades of use and corresponding comfort regarding manageable side-effect profiles with a minimum of serious side effects. Approved $\beta$ 


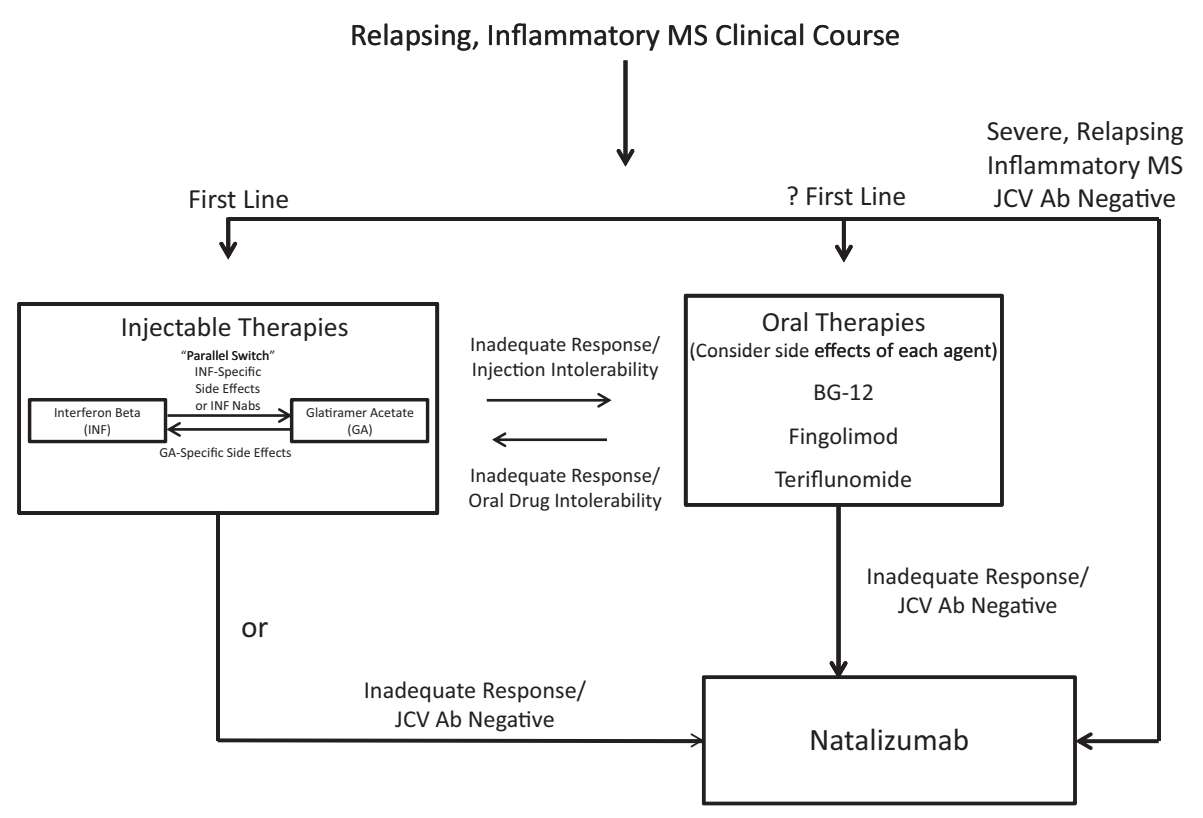

Fig. 2 Treatment algorithm for selection and switching of approved immunomodulatory multiple sclerosis (MS) medications. Note most selection and switching of MS medications lack strong evidence-based recommendations. Natalizumab should be used only with extreme caution in JCV Ab positive patients. JCV, John Cunningham virus; Ab, antibodies.

interferons are interferon $\beta$-1a subcutaneously thrice weekly (Rebif, EMD Serono, Inc., Rockland, Massachusetts) or intramuscularly once weekly (Avonex, Biogen Idec, Weston, Massachusetts) and interferon $\beta$-1b subcutaneous every other day injections (Betaseron/Betaferon, Bayer HealthCare, Leverkeusen, Germany; Extavia, Novartis, Basel, Switzerland). Glatiramer acetate (Copaxone, Teva Pharmaceuticals, Petah Tikva, Israel) is given subcutaneously on a once daily basis. Each of these injectable medications is effective in reducing clinical attacks and new MRI lesions. Parenteral therapy and mode of injection, however, is the main drawback of these medications. Interferon-specific side effects include flu-like symptoms (myalgias, headache, malaise) often improving within 2 to 3 months of therapy. Liver enzyme monitoring is recommended in patients treated with the interferon medications. Rarely, depression may worsen in these patients. Glatiramer acetate overall is well tolerated; however, flushing, eosinophilia, and rare allergic reactions may complicate therapy. Additionally, injection-site reactions may evolve into skin lipoatrophy. Combination therapy with interferon $\beta$-1aintramuscularly once weekly and glatiramer acetate does not appear to be significantly more efficacious than monotherapy. ${ }^{22}$

Since 2010, a new era has begun in the treatment of RRMS with the availability and approval of oral medications. Oral MS medications are now an attractive option for some patients and new agents continue to be introduced and approved. MS patients resistant to injection therapy in particular may select from an increasing number of oral medications now available. Currently approved oral MS medications are fingolimod (Gilenya, Novartis, Basel, Switzerland), ${ }^{23}$ teriflunomide (Aubagio, Genzyme, Cambridge, MA), ${ }^{24}$ and BG-12 (Tecfidera, Biogen Idec, Weston, Massachusetts). Each oral medication comes with their own side-effect profiles that need to be tailored to the individual patient. With fingolimod, first-dose monitoring of heart rate and blood pressure for minimum of 6 hours is required as is serological evaluation for varicella zoster virus immunity, ophthalmologic evaluation for macular edema both at baseline and repeated in 3 to 4 months and annually in those with diabetes mellitus or uveitis. ${ }^{25}$ Rare, initially unexplained sudden deaths have occurred in patients taking fingolimod; therefore, evaluation of cardiac status and antihypertensive regimens are required. Health-related warnings for teriflunomide include that of elevated liver enzymes and possible hepatoxicity and risk of teratogenicity. BG-12 may be associated with flushing.

Natalizumab (Tysabri, Biogen Idec, Weston, Massachusetts) is generally considered a second-line MS medication for patients with treatment-resistant disease, given its highly robust reduction in clinical relapses and MRI lesions. ${ }^{26}$ Occasionally, it is considered a useful first-line option if a highly inflammatory process is seen at onset with multifocal or severe repeated attacks early in the disease course. Natalizumab is prescribed through the TYSABRI Outreach: Unified Commitment to Health (TOUCH) prescribing program for patients in the United States given its association in some patients with the development of PML. ${ }^{27}$ Testing for prior exposure to the John Cunningham virus (JCV) by an enzymelinked immunosorbent assay- (ELISA-) based serological test is recommended. JCV seronegative patients are at a greatly reduced risk of PML, but need to be retested every 6 months to assure against new JCV exposure. Those patients seropositive for JCV Ab and particularly those with prior exposure to immunosuppressive drugs and treated for 2 years or more are at elevated risk for PML. Natalizumab should be discontinued in patients suspected to have PML and where plasma exchange to remove the drug is recommended. ${ }^{28}$ 
Discontinuation of natalizumab requires caution; an immune reconstitution inflammatory syndrome (IRIS) may occur. ${ }^{29}$ IRIS is a poorly understood corticosteroid-responsive inflammatory condition.

Alemtuzumab may be approached as a potential secondline medication; there are some safety concerns such as autoimmune thyroid disease and idiopathic thrombocytopenic purpura. $^{30,31}$ Mitoxantrone (Novantrone, EMD Serono, Inc., Rockland, Massachusetts) may be considered a secondor third-line agent even though it has current FDA approval; it is associated with severe side effects such as dose-related cardiotoxicity and delayed hematologic malignancies. Additional third-line agents such as cyclophosphamide ${ }^{32}$ or rituximab $^{33}$ currently lack definitive therapeutic approval, but may be occasionally considered where a rapid and reliable antiinflammatory effect is desired and the approved medications are not options.

\section{How Are MS Medications Switched?}

Parallel switching may be a convenient term for recommending a change in MS medications entirely within a drug class or between drug classes where lack of therapeutic efficacy was attributed simply to medication dosage or within a therapeutic "level" of antiinflammatory property where treatmentspecific side effects are the main drawback (-Fig. 2). An example of parallel switching within a drug class would be cases where a patient with lower therapeutic effect than desired went from a lower dose interferon $\beta$-1a intramuscular injection once weekly to interferon $\beta$-1a subcutaneous preparation given thrice weekly. ${ }^{34}$ Alternatively, if interferonspecific side effects, number of injections per week or subcutaneous skin reactions were the concern an opposite switch between $\beta$ - interferon preparations could be considered. An example of parallel switching between drug classes within a presumed similar level of antiinflammatory property would be evidenced when tolerability of interferon-specific side effects was the main concern and a switch to noninterferon glatiramer acetate could be considered. The development of interferon-neutralizing antibodies that limit their antiinflammatory effect may also indicate a parallel switch to glatiramer acetate. $^{35}$

Changing MS medications from first-line agents to secondline therapies may be needed when greater antiinflammatory potency is deemed to be required. This may be at the risk of a more-concerning side-effect profile. A balance has to be struck between arresting a severe inflammatory process where patients likely will have accrual of disability and the possibility of exposing the patient to greater side effects.

Intolerability of immunomodulatory medications remains common, and an assessment of whether immunomodulatory therapy is entirely necessary in every MS patient needs to be considered. Those with exceedingly low or no relapses over many years and those with few, if any, new accrual of MRI lesions-especially if they are experiencing the immunomodulatory medication side effects-could be considered for a discontinuation of therapy and observance off of the medications. Some patients maintain a relatively benign disease course based on accrual of clinically evident disability off immunomodulatory medications and this needs to be kept in mind.

\section{When Should Patients Stop Using Immunomodulatory Therapy?}

There are no definitive guidelines to assess when a continuation of a drug is futile or not. Both initiation and discontinuation of MS therapies require a shared decision-making model between the patient and his or her physician. ${ }^{36}$ This includes reviewing the therapeutic goals and reexamination of the patient's current clinical course, particularly as to whether they have developed SPMS. As none of the immunomodulatory medications convincingly arrest or favorably alter SPMS, these patients may be considered as candidates for possible discontinuation, perhaps particularly when ambulatory impairment milestones have been accrued and in older patients where a recurrence of clinically significant new inflammatory disease is less common. MRI findings may assist in this evaluation as well, when patients have had few, or no, new inflammatory MS lesions over a prolonged interval.

\section{Future Therapies}

There are many continuing unmet therapeutic needs for MS patients. Particularly notable is the lack of convincing therapies for patients with SPMS and PPMS. High financial cost of therapies remains a major burden as does imperfect tolerability. A major question remains whether we can reliably prevent long-term MS disability with our current antiinflammatory medications; if not, will better understanding of progressive MS multiple sclerosis lead to neuroreparative, neuroprotective, or other therapies required. Regardless, the advances of the last two decades remain remarkable in furthering our knowledge about MS and its therapy.

\section{References}

1 Polman CH, Reingold SC, Banwell B, et al. Diagnostic criteria for multiple sclerosis: 2010 revisions to the McDonald criteria. Ann Neurol 2011;69(2):292-302

2 Beck RW, Cleary PA, Anderson MM Jr, et al; The Optic Neuritis Study Group. A randomized, controlled trial of corticosteroids in the treatment of acute optic neuritis. N Engl J Med 1992;326 (9):581-588

3 Metz LM, Sabuda D, Hilsden RJ, Enns R, Meddings JB. Gastric tolerance of high-dose pulse oral prednisone in multiple sclerosis. Neurology 1999;53(9):2093-2096

4 Staff NP, Lucchinetti CF, Keegan BM. Multiple sclerosis with predominant, severe cognitive impairment. Arch Neurol 2009;66(9):1139-1143

5 Barkhof F, Rocca M, Francis G, et al; Early Treatment of Multiple Sclerosis Study Group. Validation of diagnostic magnetic resonance imaging criteria for multiple sclerosis and response to interferon beta1a. Ann Neurol 2003;53(6):718-724

6 Fortini AS, Sanders EL, Weinshenker BG, Katzmann JA. Cerebrospinal fluid oligoclonal bands in the diagnosis of multiple sclerosis. Isoelectric focusing with IgG immunoblotting compared with high-resolution agarose gel electrophoresis and cerebrospinal fluid IgG index. Am J Clin Pathol 2003;120(5):672-675

7 Gronseth GS, Ashman EJ; Report of the Quality Standards Subcommittee of the American Academy of Neurology. Practice 
parameter: the usefulness of evoked potentials in identifying clinically silent lesions in patients with suspected multiple sclerosis (an evidence-based review): Report of the Quality Standards Subcommittee of the American Academy of Neurology. Neurology 2000;54(9):1720-1725

8 Miller DH, Weinshenker BG, Filippi M, et al. Differential diagnosis of suspected multiple sclerosis: a consensus approach. Mult Scler 2008;14(9):1157-1174

9 Okuda DT, Mowry EM, Beheshtian A, et al. Incidental MRI anomalies suggestive of multiple sclerosis: the radiologically isolated syndrome. [see comment][erratum appears in Neurology. 2009 Apr 7;72(14):1284] Neurology 2009;72(9):800-805

10 Siva A, Saip S, Altintas A, Jacob A, Keegan BM, Kantarci OH. Multiple sclerosis risk in radiologically uncovered asymptomatic possible inflammatory-demyelinating disease. Mult Scler 2009;15(8):918927

11 Okuda DT, Mowry EM, Cree BAC, et al. Asymptomatic spinal cord lesions predict disease progression in radiologically isolated syndrome. Neurology 2011;76(8):686-692

12 Miller D, Barkhof F, Montalban X, Thompson A, Filippi M. Clinically isolated syndromes suggestive of multiple sclerosis, part I: natural history, pathogenesis, diagnosis, and prognosis. Lancet Neurol 2005;4(5):281-288

13 Miller D, Barkhof F, Montalban X, Thompson A, Filippi M. Clinically isolated syndromes suggestive of multiple sclerosis, part 2: nonconventional MRI, recovery processes, and management. Lancet Neurol 2005;4(6):341-348

14 Jacobs LD, Beck RW, Simon JH, et al; CHAMPS Study Group. Intramuscular interferon beta-1a therapy initiated during a first demyelinating event in multiple sclerosis. N Engl J Med 2000;343 (13):898-904

15 Kappos L, Freedman MS, Polman CH, et al; BENEFIT Study Group. Effect of early versus delayed interferon beta-1b treatment on disability after a first clinical event suggestive of multiple sclerosis: a 3-year follow-up analysis of the BENEFIT study. Lancet 2007;370(9585):389-397

16 Comi G, Martinelli V, Rodegher M, et al; PreCISe study group. Effect of glatiramer acetate on conversion to clinically definite multiple sclerosis in patients with clinically isolated syndrome (PreCISe study): a randomised, double-blind, placebo-controlled trial. Lancet 2009;374(9700):1503-1511

17 Miller DH, Leary SM. Primary-progressive multiple sclerosis. Lancet Neurol 2007;6(10):903-912

18 Wolinsky JS, Narayana PA, O'Connor P, et al; PROMiSe Trial Study Group. Glatiramer acetate in primary progressive multiple sclerosis: results of a multinational, multicenter, double-blind, placebocontrolled trial. Ann Neurol 2007;61(1):14-24

19 Goodin DS, Reder AT, Ebers GC, et al. Survival in MS: a randomized cohort study 21 years after the start of the pivotal IFN $\beta-1 \mathrm{~b}$ trial. Neurology 2012;78(17):1315-1322

20 Shirani A, Zhao Y, Karim ME, et al. Association between use of interferon beta and progression of disability in patients with relapsing-remitting multiple sclerosis. JAMA 2012;308(3):247256

21 Mikol DD, Barkhof F, Chang P, et al; REGARD study group. Comparison of subcutaneous interferon beta-1a with glatiramer acetate in patients with relapsing multiple sclerosis (the REbif vs Glatiramer Acetate in Relapsing MS Disease [REGARD] study): a multicentre, randomised, parallel, open-label trial. Lancet Neurol 2008;7(10):903-914

22 Lublin FD, Cofield SS, Cutter GR, et al; for the CombiRx Investigators. Randomized study combining interferon and glatiramer acetate in multiple sclerosis. Ann Neurol 2013

23 Cohen JA, Barkhof F, Comi G, et al; TRANSFORMS Study Group. Oral fingolimod or intramuscular interferon for relapsing multiple sclerosis. N Engl J Med 2010;362(5):402-415

24 O'Connor P, Wolinsky JS, Confavreux C, et al; TEMSO Trial Group. Randomized trial of oral teriflunomide for relapsing multiple sclerosis. N Engl J Med 2011;365(14):1293-1303

25 Pelletier D, Hafler DA. Fingolimod for multiple sclerosis. N Engl J Med 2012;366(4):339-347

26 Goodin DS, Cohen BA, O'Connor P, Kappos L, Stevens JC; Therapeutics and Technology Assessment Subcommittee of the American Academy of Neurology. Assessment: the use of natalizumab (Tysabri) for the treatment of multiple sclerosis (an evidencebased review): report of the Therapeutics and Technology Assessment Subcommittee of the American Academy of Neurology. Neurology 2008;71(10):766-773

27 Kleinschmidt-DeMasters BK, Miravalle A, Schowinsky J, Corboy J Vollmer T. Update on PML and PML-IRIS occurring in multiple sclerosis patients treated with natalizumab. J Neuropathol Exp Neurol 2012;71(7):604-617

28 Khatri BO, Man S, Giovannoni G, et al. Effect of plasma exchange in accelerating natalizumab clearance and restoring leukocyte function. Neurology 2009;72(5):402-409

29 Tan IL, McArthur JC, Clifford DB, Major EO, Nath A. Immune reconstitution inflammatory syndrome in natalizumab-associated PML. Neurology 2011;77(11):1061-1067

30 Coles AJ, Compston DA, Selmaj KW, et al; CAMMS223 Trial Investigators. Alemtuzumab vs. interferon beta-1a in early multiple sclerosis. N Engl J Med 2008;359(17):1786-1801

31 Coles AJ, Twyman CL, Arnold DL, et al; CARE-MS II investigators. Alemtuzumab for patients with relapsing multiple sclerosis after disease-modifying therapy: a randomised controlled phase 3 trial. Lancet 2012;380(9856):1829-1839

32 Boster A, Edan G, Frohman E, et al; Multiple Sclerosis Clinical Research Center, Department of Neurology, Wayne State University School of Medicine. Intense immunosuppression in patients with rapidly worsening multiple sclerosis: treatment guidelines for the clinician. Lancet Neurol 2008;7(2):173-183

33 Hauser SL, Waubant E, Arnold DL, et al; HERMES Trial Group. B-cell depletion with rituximab in relapsing-remitting multiple sclerosis. N Engl J Med 2008;358(7):676-688

34 Panitch H, Goodin DS, Francis G, et al; EVIDENCE Study Group. EVidence of Interferon Dose-response: European North American Comparative Efficacy; University of British Columbia MS/MRI Research Group. Randomized, comparative study of interferon beta-1a treatment regimens in MS: The EVIDENCE Trial. Neurology 2002;59(10):1496-1506

35 van der Voort LF, Gilli F, Bertolotto A, et al. Clinical effect of neutralizing antibodies to interferon beta that persist long after cessation of therapy for multiple sclerosis. Arch Neurol 2010;67 (4):402-407

36 Pittock SJ, Weinshenker BG, Noseworthy JH, et al. Not every patient with multiple sclerosis should be treated at time of diagnosis. [see comment] Arch Neurol 2006;63(4):611-614 